\title{
The weathering-modified iridium record of a new Cretaceous-Palaeogene site at Lechówka near Chełm, SE Poland, and its palaeobiologic implications
}

Grzegorz Racki, Marcin Machalski, Christian Koeberl, and Marian Harasimiuk

Acta Palaeontologica Polonica 56 (1), 2011: 205-215 doi: http://dx.doi.org/10.4202/app.2010.0062

In the light of integrated biostratigraphic and geochemical data, a complete shallow-marine succession across the Cretaceous-Palaeogene (K-Pg) boundary, with the critical boundary clay coupled with a burrowed siliceous chalk ("opoka" in Polish geological literature), possibly equivalent of the basal Danian Cerithium Limestone in Denmark, has been discovered at Lechówka near Chełm, SE Poland. An extraterrestrial signature marking the K-Pg boundary is confirmed by anomalously high amounts of iridium (up to $9.8 \mathrm{ppb}$ ) and other siderophile elements (especially $\mathrm{Au}$ and $\mathrm{Ni}$ ), as well as by an elevated $\mathrm{Ir} / \mathrm{Au}$ ratio consistent with a chondrite meteoritic composition. The major positive iridium spike surprisingly occurs in Maastrichtian marls, 10 $\mathrm{cm}$ below the boundary clay interval, which can be explained by diagenetic mobilisation and re-concentration of the impact-derived components. Thus, intensively infiltrating, humic acid-rich ground waters during the long-lasting Palaeogene weathering in tropical humid regimes were probably responsible not only for the large-scale decalcification of the Lechówka section, but also for both downward displaced position of the iridium enrichment, a dispersed profile of this anomaly and its significantly lessened value, but still approaching an increase by a factor of 100 . This modified record of the K-Pg boundary event points to a careful reconsideration of the iridium anomaly as a trustworthy marker for studying the extinction patterns across the K-Pg boundary, as supported by the recent data from New Jersey, USA.

Key words: Iridium anomaly, lithology, biostratigraphy, extinctions, geochemistry, Cretaceous-Palaeogene boundary SE Poland.

Grzegorz Racki [racki@twarda.pan.pl] and Marcin Machalski [mach@twarda.pan.pl

], Institute of Paleobiology, Polish Academy of Sciences, ul. Twarda

51/55, PL-00-818 Warszawa, Poland; Christian Koeberl [christian.koeberl@univie.ac.at

], Department of Lithospheric Research, University of

Vienna, 1090 Vienna, Austria, and Natural History Museum,

Burgring 7, A-1010 Vienna, Austria; Marian Harasimiuk [marian.harasimiuk@ poczta.umcs.lublin.pl], Department of Geology and Protection of Lithosphere, Institute of Earth Sciences, Maria Curie Skłodowska University, Al. Kraśnicka 2cd, PL-20-718 Lublin, Poland. 
This is an open-access article distributed under the terms of the Creative Commons Attribution License (for details please see creativecommons.org), which permits unrestricted use, distribution, and reproduction in any medium, provided the original author and source are credited.

FaF 